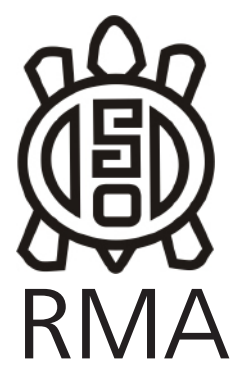

Homenaje a

\title{
El Doctor Alberto Rex González y la
} Arqueología Ambiental

\author{
Héctor D'Antoni* \\ *Investigador Emérito asociado al NASA Ames Research \\ Center, Moffett Field, California, Estados Unidos. \\ E-mail: hector.dantoni@gmail.com
}

Alberto Rex Gonzalez

Escribir sobre el comienzo de la arqueología ambiental en la Argentina y el papel que le tocó desempeñar al Dr. Rex González contendrá un componente autobiográfico, ya que el Jefe de la División Arqueología del Museo de La Plata y codirector de mi tesis doctoral, puso en mis manos la responsabilidad de desarrollarla. Se trata de un trabajo incompleto, ya que los graves hechos que afectaron al país en la década de 1970 interrumpieron ese fascinante proceso. Afortunadamente, una joven generación de arqueólogos ha retomado algunas de esas líneas, las ha remozado y enriquecido con nuevas ideas y nuevas técnicas que permitirán mejorar y concluir aquello que impulsó Rex González hace casi cuatro décadas.

En 1964, al volver de su estadía en Harvard a la Facultad de Ciencias Naturales y Museo, Rex González dictó un curso anual de Arqueología Americana I (Precerámico). El curso fue sorprendente e inspirador desde el principio, cuando expuso las ideas de Richard Foster Flint, incluyendo aquellas que el famoso geólogo había desarrollado junto con nuestro compatriota, Francisco Fidalgo. La primera clase dejó en claro que el estudio de materiales precerámicos debía hacerse en consonancia con el conocimiento disponible de la geología del Cuaternario. Estos temas estaban algo alejados de nuestro interés por la prehistoria humana pero, con ese empuje que algunos de sus discípulos creemos haber heredado de él, Rex González nos dio una síntesis actualizada y profunda que mostraba la estrecha relación de la arqueología con la geología del Cuaternario y la geomorfología.

Al final de la clase nos acercamos al podio para manifestarle nuestra sorpresa y agrado por el panorama que acababa de presentar. Entonces nos dijo, "hay que integrar varias ramas de la ciencia para poder asomarse a la vida de los primeros seres humanos que poblaron este continente. Desde la etnografía a la etnohistoria y desde allí a la prehistoria hay que establecer vínculos de lo conocido con lo desconocido, inferir los procesos que condujeron de un estadio al otro y contrastar las inferencias con datos de la realidad". Yo escuché atentamente este apotegma de la arqueología científica. Hice preguntas, di alguna tímida opinión y salí de la clase con una gran alegría: esto era lo yo buscaba en la antropología. Antes de empezar la clase siguiente, Rex González se acercó y me dijo: "Después de la charla del viernes, pensé que esto le interesaría", y me dio dos números de American Antiquity de 1958 con el artículo "Ecological Interpretation in Archeology1." Esta obra pionera capturó mi interés y en buena medida decidió mi futuro. Sus autores dedican varios párrafos al análisis de polen y citan los trabajos de Iversen (en Dinamarca) y de Firbas $^{2}$ (en Alemania), pero omiten el aspecto integrador que yo creía leer entre líneas en el "moderno" análisis de polen postulado por Faegri e Iversen en 1950 en la primera versión del libro más leído en la especialidad, el "Textbook of modern pollen analysis"3. La omisión de este aspecto del análisis de polen me pareció importante y creí encontrar allí un nicho que me permitiría hacer algo original. Rex González estuvo de acuerdo.

Conversamos sobre la cantidad de datos valiosos que encierran los pequeños restos de plantas, fragmentos de huesos de aves y conchillas y sobre la posibilidad de recobrarlos mediante zarandas finas y agua. Hablamos de la arqueología de precisión descrita en el trabajo de Hill sobre "Broken K Pueblo" en Arizona (un trabajo icónico para la "New Archeology" de los años que siguieron).

\footnotetext{
1 Meighan, C.W., D.M. Pendergast, B.K Swartz Jr. y M.D. Wissler, 1958, Ecological Interpretation in Ecology Part I, American Antiquity Vol. 24 (1): 1-23. y Part 2, Vol. 24 (2): 131-150.

2 Antes que yo estableciese en nuestro país la metodología del análisis ecológico de polen desde 1971, un discípulo del Prof. Firbas, el botánico argentino, Dr. Federico Vervoorst (autor de obras importantes como el estudio de las comunidades vegetales de la Depresión del Salado) había realizado investigaciones de polen actual y del Cuaternario que no publicó

3 El efecto de este libro fue colosal y la palabra "moderno" salió de su título: era no sólo moderno sino la forma más avanzada de hacer análisis de polen
} 
Hablamos de las tecnologías que la arqueología introducía en su instrumental, como las fuentes de radiación ultravioleta o infrarroja para hacer visible y registrar partes de la pintura rupestre que de otro modo estarían perdidas para siempre. El trabajo de Semenov, que usó lupas estereoscópicas para buscar marcas de uso en instrumentos de piedra. Esta arqueología, que se conectaba con el pensamiento sintetizador de Gordon Childe, se ocupaba también de la evidencia menuda en busca de claves para explorar el desarrollo de la cultura que, con obras menos espectaculares que las de Egipto o Mesoamérica, satisfacía las necesidades de su gente. Nos detuvimos un poco más en la antropología norteamericana de Franz Boas y sus prominentes discípulos, que Rex González conocía personalmente. Hablamos de los estudios cuantitativos y de las coordenadas funcional, cronológica y corológica propuestas por Childe. También de la contribución de Willard Libby con el método de datación por radiocarbono. Ford, la seriación, Meggers y Evans, lo mismo que Binford, Patty Jo Watson, y otros pasaron por nuestra conversación.

Hubo una pausa, Rex González se acomodó el bigote como solía hacer mientras ordenaba sus pensamientos, carraspeó, y dijo: "Para no interesarle la arqueología, está usted muy bien informado" y su puso a reír. Me dio vergüenza recordar que en la clase anterior yo le había dicho que no sabía a qué iba a dedicarme pero seguro que no a la arqueología. Esas cosas que uno dice e inmediatamente se arrepiente pero las palabras ya dichas no están bajo nuestro control y tienen existencia propia. Es posible que Rex González haya visto mi cambio de intereses como un éxito de su esfuerzo por ponernos al día con lo que pasaba en el mundo y, si pensó eso, tuvo razón.

Con un arreglo precario, el Dr. Sergio Archangelsky me dejó preparar algunas muestras de polen actual y algunos sedimentos bajo la supervisión de Graciela Pezzani quien con bondad y paciencia me guió por los protocolos de la extracción del polen mediante hidrólisis ácida. Consulté a los profesores que más respetaba (Rex González, Dawson, Cabrera y Fidalgo) y todos estuvieron de acuerdo en que tomase el curso de Palinología que dictaba en el Museo Juan Carlos Gamerro asistido por Marta Morbelli. Al rendir el examen de esta materia a fines de 1969 fui Licenciado en Antropología.

En 1970, Rex González y Dawson fueron los directores de mi Beca de la CIC de la Universidad (que presidía el Prof. Hans Schumacher), para desarrollar un "estudio ecológico de dos regiones de contacto cultural: valliserrana y selvas occidentales". A lo largo del año mis directores me ofrecieron críticas enriquecedoras en el aspecto científico pero también en el ético y humano.

En 1970, no había en la Argentina un centro de análisis de polen del Cuaternario en el sentido de Faegri e
Iversen. Archangelsky me dijo, "Tendrá que irse afuera por un tiempo". Mis directores estuvieron de acuerdo. En 1971 gané una Beca de Graduado del Real Ministerio de Relaciones Exteriores de los Países Bajos, para estudiar Palinología del Cuaternario con el Dr. Thomas van der Hammen en la Universidad de Ámsterdam. Cuatro días después de casarme con Susana Lasta, aterrizamos en Ámsterdam donde nos esperaban van der Hammen y su esposa Anita Malo. Cuando volvía a casa después del trabajo, aprovechaba el tiempo hasta la hora de la cena para escribir el informe de progreso de mi Beca de la CIC. Ese informe muy reducido se publicó en Etnia en 1971 y está dedicado a los doctores Rex González y Dawson. Con van del Hammen aprendí lo que necesitaba, no sólo en análisis de polen sino también en ecología experimental. A su instancia visité a la Sra. van Campo en Francia, a Iversen en Dinamarca y a Erdtman en Suecia. Con todos intercambié opiniones sobre mis ideas de la palinología del desierto. Iversen me dedicó dos días para analizar los detalles finos de mi idea, que contrastaba con el paradigma que él había establecido para Europa del Norte y después de examinarlo cuidadosamente me dio su apoyo. Informé todos estos progresos a van der Hammen y a mis directores argentinos.

Al llegar a La Plata en 1972, Rex González me asignó el amplio despacho junto a su oficina, el Dr. Edgardo Rolleri (Decano de la Facultad) me dio un poco de apoyo para el equipamiento y otro poco vino de mi madre. Así se montó el primer Laboratorio de Paleoecología en la División Arqueología del Museo de La Plata. En cuanto a la difusión de este esfuerzo de la División, presenté mis conclusiones en cursos, clases y reuniones científicas nacionales. Hacía algún tiempo que investigaba la etnobotánica del algarrobo (Prosopis spp.) y llevé una copia del informe de ese trabajo a la Primera Reunión de Ecología Argentina realizada en Vaquerías (Córdoba) entre el 24 y el 29 de Abril de 1972 organizada por los doctores Ricardo Luti, Enrique Bucher y María Cristina Báez. Una reunión fecunda, enriquecedora para quienes se ocupaban de las relaciones de la ecología con la arqueología. Entre las personalidades venidas del exterior estaban Charles Lowe (de la Universidad de Arizona) y nuestro compatriota Otto Solbrig (de la de Harvard). Solbrig me pidió una copia del trabajo del algarrobo mientras conversábamos con Rex González sobre la importancia de la etnobotánica y el camino a la paleoetnobotánica que había tomado Margaret Towle en su libro, Ethnobotany of Pre-Columbian Perú. Años después, mi artículo del algarrobo, enriquecido con contribuciones de Solbrig y traducido por él al inglés se publicó en el libro de Beryl Sympson, "Mesquite, its biology in two desert ecosystems" del Programa Biológico Internacional (IBP). Nuestro artículo refleja esa integración de ramas de la ciencia y ese proceso del pasado al presente de las culturas del Noroeste Argentino. Cabe señalar que gracias a Rex González fuimos el grupo de arqueólogos elegido por los organizadores para asistir a una reunión fundacional 
de la ecología argentina, donde teníamos mucho que preguntar pero también mucho que ofrecer.

Rex González nos encargó a José Togo y a mí que estudiáramos algunos materiales de las excavaciones de Pampa Grande, en la Provincia de Salta. Unas pocas muestras de sedimentos estratificados de la Cueva El Litro permitieron detectar un cambio de clima, desde un ámbito de pastizal de altura a uno más benigno marcado por el ascenso del bosque de alisos. Otros materiales estimularon nuestra imaginación. Entre las ofrendas que acompañaban a los paquetes funerarios enterrados en urnas de cerámica selladas herméticamente, había excrementos animales. También se hallaban excrementos similares fuera de las urnas, en el relleno de abrigos rocosos como las cuevas El Litro y Los Aparejos. En lugar de analizarlos en conjunto por su contenido, extrajimos el polen de cada hez por separado, aumentando 30 veces el trabajo de laboratorio. El esfuerzo fue pagado con creces cuando se vio que el polen de las heces encontradas fuera de las urnas describía un ambiente natural y por ende las heces podían ser de animales que comían libremente cuanto alimento encontraban a su alrededor. En cambio, el polen de las heces incluidas en el ajuar funerario mostraban predominancia (de hasta el 70\%) del polen de una hierba (Plantago sp.) que es indicadora de suelos perturbados. Propusimos una hipótesis: los excrementos encontrados en los sedimentos correspondían a animales salvajes como el guanaco (Lama guanicoe), que visitaban los sitios de enterratorios humanos fuera de la época de los rituales mientras que los hallados en las urnas correspondían a animales domésticos como la llama (Lama glama), que se alimentaban en las áreas de cultivo. El entusiasmo producido por los resultados de la copropalinología nos llevó a consultar al Dr. Mario A. Lasta sobre la posibilidad de analizar heces humanas de la época de los enterratorios. El resultado fue un diagnóstico preliminar de Oxiurus sp., un parásito intestinal que hasta entonces se consideraba traído por los europeos. En la primavera de 1972, José Togo, Roberto Crowder y yo viajamos al valle del Hualfín en Catamarca. El objetivo era tomar muestras de polen actual provenientes de las distintas fajas de vegetación que se veían en las laderas del Valle y también buscar respuesta a algunas preguntas de carácter ambiental. La parte más laboriosa del trabajo de campo era hacer secciones transversales al valle ("transectas"), censar la vegetación y tomar muestras de suelo en los mismos espacios rectangulares de $2 \times 300$ metros en que hacíamos los censos. Esto nos permitió hacer una descripción detallada de la vegetación del valle. Pero la transecta extendida entre Corral de Ramas y el Río Hualfín nos ofreció una inesperada validación de nuestra hipótesis sobre las heces animales encontradas dentro de las urnas funerarias de Pampa Grande. En efecto, en Corral de Ramas, una familia de agricultores de apellido Titos, (probablemente de origen Inca) tenía sus llamas en los cuadros de cultivo en barbecho, usando las deyecciones de las llamas como abono. En los cuadros de cultivo convertidos en corrales vimos que el suelo estaba cubierto de hierbas del género Plantago. Eso explicaba la dominancia de Plantago (70\%) en los espectros de polen de los excrementos usados como ofrendas funerarias en Salta y subrayaban la persistencia de esta técnica de abono por más de 1200 años. En efecto, estas prácticas que unían la agricultura con la explotación ganadera se remontaban a la cultura Candelaria fechada en Pampa Grande en el año 700 de nuestra era. Rex González estaba entusiasmado con estos hallazgos que no tenían antecedentes en la bibliografía y mostraban que su modo de conversar con sus discípulos y darles amplia libertad tenía buenos resultados.

Hacia fines de 1972, el famoso arqueólogo norteamericano Richard MacNeish visitaba a Rex González en el Museo de La Plata. El anfitrión llevó a su visitante a cada una de las oficinas de la División y presentó a los miembros de su equipo y MacNeish hizo preguntas y comentarios. Cuando llegó mi turno, MacNeish me hizo varias preguntas interesantes, habló de especialistas que trabajaban en líneas vecinas a las mías pero, sobre todo, repitió su recomendación de que yo fuera a Estados Unidos. La persona que él creía más afín a mis intereses era Paul S. Martin, el paleontólogo de la Universidad de Arizona en Tucson. La visita de MacNeish y el entusiasmo con que Rex González hablaba de mi trabajo me dejaron una sensación grata y una idea vaga sobre la posibilidad de volver a salir del país. No me entusiasmaba tanto porque la vida diaria en la División Arqueología era grata y estimulante. Teníamos experiencias compartidas, una interesante mezcla de tradiciones académicas y un jefe a quien todos estimábamos y respetábamos. Era difícil imaginar un lugar mejor para mis investigaciones.

La posibilidad de ir a trabajar a un centro de excelencia reconocido en mi especialidad era una gran tentación para todos y mis colegas y amigos María Delia Arena, José Antonio Pérez Gollán, Ovaldo Heredia y Pedro Krapovickas me hicieron ver que esas oportunidades son raras en nuestra profesión. ¿Quién era Paul S. Martin? Yo sabía del arqueólogo de la New Archeology, pero no del paleontólogo del que me había hablado MacNeish. La respuesta vino a mí en unas dos semanas. En una extensa carta, el Dr. Paul S. Martin me felicitaba por el diagrama preliminar del polen de la Gruta del Indio que le había enviado Humberto Lagiglia. Martin me hablaba de su interés por la Gruta mendocina que tenía restos del perezoso Mylodon, análogo del Nothrotherium de la Rampart Cave que él había estudiado en el Gran Cañón del Colorado. Martin buscaba pruebas de la convivencia de estos perezosos del Pleistoceno con el hombre, para poder validar su hipótesis sobre la extinción de estos animales a causa de la excesiva matanza ("over killing") que hacían los humanos. Nos conocimos en San Rafael de Mendoza en Enero de 1973 y él también me instó a pasar una temporada en su Laboratorio de Tucson. Por su parte, Heredia y Pérez Gollán reconstruían la prehistoria 
del Valle del Ambato y me invitaron al trabajo de campo para hacerme cargo del estudio paleoambiental de la localidad.

Con la co-dirección de Rex González y Dawson, ingresé a la Carrera del Investigador para trabajar en arqueología ambiental. Poco después gané una beca de la Fundación Guggenheim para investigar el polen actual y del Cuaternario argentino. En Junio de 1975 llegué a Tucson, al Laboratorio de Estudios Paleoambientales de la Universidad de Arizona. Preparé una palinoteca de referencia del desierto argentino y una serie de muestras de perfiles arqueológicos del Noroeste y de la Patagonia. Además de varios artículos de palinología argentina, publicamos (con Vera Markgraf) la "Pollen Flora of Argentina" y yo, fiel al objetivo de arqueología ambiental publiqué un libro en castellano: "Arqueoecología. El hombre en los ecosistemas del pasado a través de la palinología" que fue usado como texto en la Escuela Nacional de Antropología de México durante más de dos décadas. Pensé que esta obra ayudaría a mis colegas arqueólogos a entender los alcances del análisis de polen como herramienta de la arqueología ambiental para usarlo en mis clases del Museo. Pero no volví a ser docente del Museo de La Plata.
En Octubre de 1976 las autoridades de facto del CONICET me ordenaron volver a la Argentina so pena de perder mi cargo en Carrera del Investigador. Antes de salir de Tucson fui a saludar a mis colegas y amigos del Museo de Arqueología. El Prof. Emil Haury, emérito de la Universidad de Columbia me dio saludos para su ex alumno Rex González. El Director, Dr. Raymond Thompson, me pidió que ofreciera a Rex González en nombre del claustro de docentes e investigadores, el cargo de Profesor Extraordinario del Departamento de Arqueología por el tiempo que él quisiera. En La Plata encontré nuestro lugar de trabajo en decadencia a falta de un jefe de la estatura intelectual de Rex González. En la ciudad imperaba el terror, los estudiantes morían o desaparecían y la gente, que vivía en pánico, no hablaba. Visité a mi maestro en su casa de la Calle 1 y volvió a deleitarme con su análisis lúcido, su dignidad ante la infamia de su separación del cargo y su decisión de quedarse contra todos los riesgos a resistir desde adentro este nuevo revés de la historia argentina. Me agradeció emocionado la invitación de Thompson y el interés de Haury pero no aceptó la generosa invitación.

Volví a Arizona como Profesor de Palinología para Arqueólogos. Un año después gané una Beca Humboldt

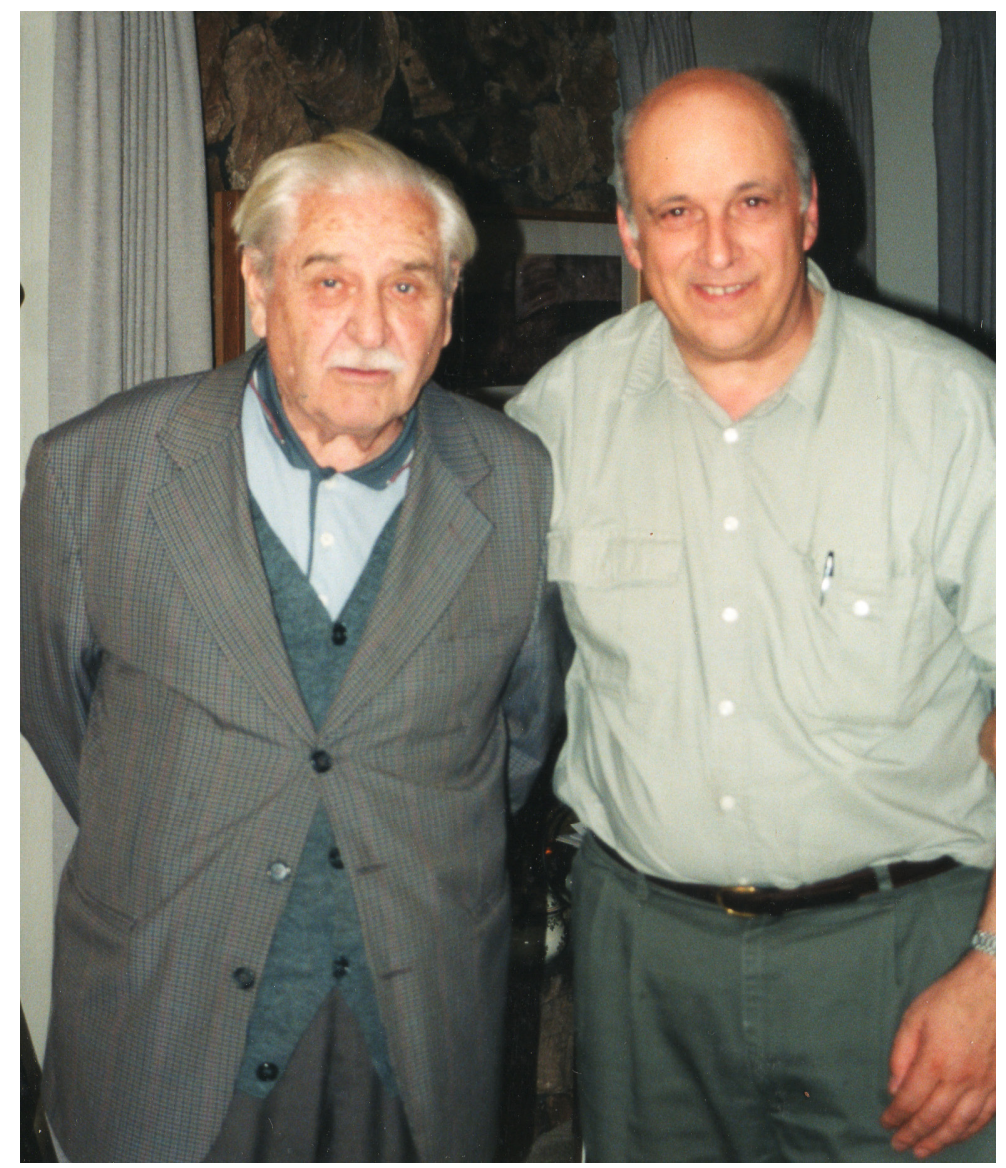

En 2002, el Dr. Rex Gonzalez viajó a Washington D.C. para recibir un Premio de la Smithsonian Institution por sus contribuciones a la arqueología. De regreso a la Argentina, visitó al autor en su casa de Morgan Hill, California. 
para hacer mi postdoctorado en Ecología Vegetal en el Instituto de Botánica de Hohenheim (Stuttgart). Fue una elección acertada por el alto nivel del Instituto y por la oportunidad de interesar a mi anfitrión, el Prof. Burkard Frenzel, en los métodos que desarrollé con técnicas estadísticas bien establecidas. Revisamos juntos algunos perfiles de la región de Eifel. Uno de esos análisis sirvió para un artículo titulado, "Estructuras Temporales en un Perfil Polínico del Occidente Alemán" que presenté en 1980 al Simposio Sobre Paleobotánica y Palinología celebrado en la Ciudad de México con la co-autoría del Prof. Frenzel. Por mi parte, además de hacer las investigaciones proyectadas para mi postdoctorado comencé a concebir un proyecto para regresar a la Argentina en una fecha aun incierta. El proyecto tenía el objetivo de formar en Argentina una "masa crítica" de palinólogos del Cuaternario que usaran el método que yo había compilado en Arizona. La colaboración con los arqueólogos era un objetivo de primera importancia.

El proyecto era satisfactorio pero la probabilidad de volver a La Plata y recomponer el ambiente de la División Arqueología bajo la dirección de Rex González era muy baja. Estaba considerando una oferta de trabajo permanente en Alemania cuando recibí la llamada de un estimado y respetado colega germano-argentino, el Prof. Dr. Wolfgang Volkheimer. Volkheimer me instó a volver a la Argentina donde, según su opinión, las condiciones se iban normalizando lentamente. Él pensaba que era necesario que quienes teníamos algo que ofrecer volviéramos cuanto antes. Volkheimer me hablaba con el entusiasmo y la cordialidad que lo caracterizan. Era claro que sería palinólogo en vez de arqueólogo ambiental, que era mi objetivo. ¿Cuál era el grado de libertad que había recuperado la Argentina desde el horror que pude ver y sentir en 1976?

Tenía la posibilidad de ir a México, donde el Prof. José Luis Lorenzo sabía de mi trabajo y había mostrado interés. Como discípulo de Rex González, fui recibido cordialmente en el Departamento de Prehistoria del Instituto Nacional de Antropología e Historia (INAH), en 1977, cuando entregué el manuscrito de mi libro, "Arqueocología. El Hombre en los Ecosistemas del Pasado a Través de la Palinología" para su evaluación. Por supuesto extrañaba a la gente de La Plata, pero los profesores José Luis Lorenzo, Javier García Bárcena, Lorena Mirambell, Fernando Sánchez Martínez y, por cierto, mi compatriota José Antonio Pérez Gollán, además de varios estudiantes avanzados, hicieron que mi estadía en la Capital de México fuese productiva y placentera. El objetivo de este contrato era desarrollar la Arqueología Ambiental. Escribí y puse en marcha el Proyecto Pico de Orizaba. Dicté un curso de Palinología del Cuaternario al que asistieron arqueólogos, geólogos del petróleo de PEMEX y una ex alumna mejicana de mis clases de Etnobotánica en el Museo de La Plata. Mi salud, en cambio, no respondió bien al ambiente de la Ciudad de
México. Eso y algunas cuestiones familiares en Argentina me hicieron dejar la posición distinguida que me había dado el INAH y volver a mi país.

El marco de referencia que había sido para mi carrera la División Arqueología del Museo de La Plata bajo la jefatura de Rex González había desparecido. La Universidad Nacional de Mar del Plata me ofreció un cargo de Profesor Titular con Dedicación Exclusiva en el Departamento de Biología de la Facultad de Ciencias Exactas y Naturales. Allí fundé el Laboratorio de Palinología. Traté de reclutar candidatos a becas de la CIC de la Provincia de Buenos Aires o del CONICET que tuviesen estudios de antropología y traté de darles temas de trabajo que incluyesen el estudio paleoambiental de sitios y localidades arqueológicas.

En 1989 gané un contrato del National Research Council para desarrollar en la NASA durante uno o dos años mi proyecto, "Pollen Analysis in Patagonia: from Space to Time" que trataba el tema de los análogos modernos desde una perspectiva nueva y poderosa. Mi actividad poco tenía que ver con la arqueología. Pronto la NASA me ofreció una posición en el máximo nivel de su planta permanente y allí pasé los últimos veinte años de mi vida científica.

Una carta de dos colegas ${ }^{4}$ del Consejo Superior de Investigaciones Científicas (CSIC) de España despertó mi adormecida pasión por la Arqueología. Los visité en Madrid varias veces y colaboré en la revisión de sus proyectos. Presenté el manuscrito de un libro que había escrito en mi casa, después del trabajo y en los fines de semana: "Arqueoecología Sistémica y Caótica" donde me ocupo de la epistemología del análisis de polen y su uso práctico en arqueología. La CSIC decide publicarlo en su colección Textos Universitarios y yo siento que he saldado una deuda de gratitud con la antropología y la arqueología que aprendí y disfruté en el Museo de La Plata.

Visité a Rex González por última vez en La Plata, acompañado por mi esposa, una hermosa mañana de Abril de 2011. El maestro nos esperaba con sus grandes ojos celestes, inquisidores como siempre. Hablamos largo rato y me preguntó repetidamente por mis hijos y nuestra felicidad. En la mesita frente a él estaba mi libro, abierto en la dedicatoria, en la que le agradecía la ciencia que me había enseñado y esa ética que él expresaba coloquialmente como "no me gusta vestirme con el ropaje ajeno". Conversaba con el viejo y querido maestro y pensaba que ser su alumno había sido un privilegio y un verdadero honor. Que con su saber y su ética había hecho de nosotros, sus discípulos, mejores personas. La emoción era difícil de controlar, le tendí mi mano y raro en mí, me quedé sin palabras. Susana vino en mi socorro: se inclinó y besó la mejilla del maestro. "Gracias Rex, ha sido

\footnotetext{
${ }^{4}$ Maribel Martínez Navarrete y Juan Vicent García.
} 
un placer volver a verlo". Susana se levantaba cuando el maestro tomó su mano y la besó, cerrando la visita con ese inolvidable gesto de caballero.

Rex González puso a la Arqueología Argentina en el mapa del mundo, fue respetado y reverenciado dentro y fuera del país y, como sucede a menudo con los grandes, fue perseguido en su tierra. Resistió de pie y después de la opresión renació con la fuerza moral y el optimismo con que guió su vida. 